\title{
Social Security in the Lockdown: A Time to Revisit the NCEUS Recommendations
}

\author{
K. P. Kannan ${ }^{1}$
}

Published online: 14 September 2020

(c) Indian Society of Labour Economics 2020

\section{Introduction}

In normal times the meaning of social security is somewhat restricted. It is about the absence or presence of some fallback mechanisms when in distress of one kind or another, as, for example, unemployment, sickness, accident/death, old age, etc. In countries with endemic poverty such as India, social security also refers to such protective schemes as Public Distribution System (PDS) for essential food, mid-day meals for children in schools, supplementary nutrition for children in pre-school age group, public employment and so on. The first set of measures are for meeting situations of adversity, while the second are measures for meeting situations of deficiency.

The meaning of social security in the face of lockdown of human activities due to the COVID-19 pandemic has changed the horizon into one of generalised insecurity in a country like India with a significant proportion of households that are poor and vulnerable. Lockdown implies instant loss of jobs and therefore, wage/earnings loss. This income loss is permanent for those workers whose wages and incomes are contingent on actual performance of work on a day-to-day basis. Such workers do not enjoy employment security or social security, and they are called informal workers (NCEUS 2008, 2009). As per 2017-18 employment data, they constitute around 370 million workers in the informal sector and a little more than 40 million in the formal sector are employed as informal workers. The former constitutes 80 per cent of the total work force, and the latter constitutes 10 per cent.

Since the first lockdown in India was announced on 22 March 2020, those migrant workers who chose to leave their location of work could not get wages even for the month of March. Given the complete lockdown, an overwhelming proportion of workers could not work for the first full month. Since then, lockdown has been announced by the state governments in selected regions and localities within their states. On the whole, it would not be an exaggeration to say that at least 40 per

\section{K. P. Kannan}

kannankp123@gmail.com

1 Centre for Development Studies, Thiruvananthapuram, India 
cent of workers in the informal sector are without jobs and hence, without wages/ incomes. For even those who are working in the formal sector, there have been reports of cuts in salaries and selective layoffs given the financial constraints of the enterprises.

But, this sudden insecurity of job and income also became insecurity of living itself for a large number of informal workers and their households. This is the prospect of contamination by COVID-19 and the consequent disability or death or suffering and death due to lack of food and their basic minimum necessities. For the migrant workers - more than 10 million of them is reported to have left their places of work and gone back to their villages - another existential insecurity in the form of leaving their place of work and not being exactly welcome into their villages added to their generalised insecurity. What we are witnessing today is nothing short of an existential crisis of enormous proportions for the poor and vulnerable.

It need not have been like this had there been a fallback mechanism for these working men and women constituting 90 per cent of the workforce. After all, India registered an unprecedented high growth rate since the mid-eighties to 2015, i.e. an uninterrupted period of 30 years by all accounts. This is where I feel a revisit of the recommendations of the National Commission for Enterprises in the Unorganised Sector (NCEUS) is in order if only to underline the fact that there were an architecture, a blueprint and a detailed work plan for instituting a comprehensive national social security system for the informal sector (consisting of both workers and enterprises) that would have provided a measure of fallback, social security, for India's insecure workers.

\section{Revisiting NCEUS Recommendations}

In the wake of the generalised lockdown in the country announced on 22 March 2020 and the resultant panic among the working poor, there was the announcement of free ration for three months in the form of food grains and some pulses. There was also an announcement of a paltry sum of Rs. 500 to be transferred to the Jan Dhan accounts of the poorer sections. These announcements and the many proposals for relief invoked issues like identification of the working poor including those migrant workers who returned to their villages, the institutional mechanisms for providing some social security and so on. I would argue that the NCEUS proposals for social security for the informal workers would have covered an overwhelming proportion of deserving households to which the state could easily add those tiny proportions of households without working members.

What are the main features of the NCEUS proposals?

These may be divided into the following two categories:

\subsection{Social Security Measures}

(1) First, the idea of identification and the availability of a list or register of informal workers as the Supreme Court asked in the wake of the exodus of migrant 
workers. The NCEUS had recommended a system of registration of all informal workers with the help of Workers Facilitation Centres (WFCs) at the local level of Village Panchayats and Municipal governments in towns. These WFCs could be designated agencies such as NGOs, trade unions or cooperative organisations/association working among the informal workers in a given locality. In the absence of such organisations, the local government itself should act as WFCs. Registration will be based on self-certification.

(2) These registered workers were to come under the State level Social Security and Welfare Boards charged with implementing a national social security scheme. The national scheme would be treated as the basic minimum to which each state government could add depending on their fiscal capacity and other regional context.

(3) There would also be a National Social Security and Welfare Board for overall supervision, distribution of a National Fund to the State Boards, policy advice, and monitoring welfare/promotional schemes for the informal workers and their families. Similarly, there will also be a State Fund to enable the state government to contribute, as add on, to the social security scheme, as well as for the activities of the State Social Security and Welfare Board.

(4) The National Fund as well as the State Funds will be dedicated ones receiving a pre-determined budgetary transfer from the central/state government(s). This is intended to insulate it from arbitrary allocation of funds by successive regimes as well as year-to-year variations by a given regime.

(5) The proposed national social security scheme was intended to create a "social floor" below which no workers should fall. It consisted of, what we may call, three pillars. The first pillar is a statutory national minimum wage based on basic needs. As per the most recent expert committee set up by this regime a national minimum wage was worked out based on basic needs and it came to Rs. 375/- a day as the national average in 2018. This would be Rs. 410 today (as against the central government's non-statutory national minimum wage of recommendation of Rs. 200) which would act as a floor level for any sectoral or state-wise minimum wages fixed from time to time. The second pillar is a social security package for meeting sickness, accident/death (insurance) and/or Provident Fund for those who are in a position to contribute or an old age state pension for those who do not have the capacity to contribute. The third pillar is the enactment of a law governing Minimum Conditions of Work to address the deplorable conditions of work in the informal sector in various parts of the country, across several occupations and activities.

(6) For those who are unemployed, the NCEUS recommended an unemployment insurance to meet situations of joblessness up to a year.

\subsection{Social Promotional Measures}

While these elements constituted the larger social security part, there was another part that addressed the question of promotion of livelihoods. This is the social promotion part. It recognised the need for basic social security to meet situations of 
deficiency such as schemes for housing, food, education and health. But the NCEUS emphasised and elaborated the need for addressing specific areas of deficiency faced by the informal workers and the informal sector. The former focused on workers, while the latter focused on enterprises. The main recommendations may be listed as follows.

(1) Skill formation and upgradation was identified as a priority area. A detailed plan of action was developed with recommendations to cover a whole range of workers and potential workers (at the school level). For purposes of policy and funding a National Mission for Development of Skills in the Unorganised Sector was proposed.

(2) The role of public employment programmes in a context of a large segment of working poor was flagged as an important agenda under promotional activities. Given the context of the National Rural Employment Guarantee Act of 2005, a number of recommendations were made to extend the scope of coverage of activities, relaxation of the cap of 100 days of employment including changing the per household stipulation into per person, extension of the public employment to urban areas, convergence with other schemes, dovetailing with social development programmes, skill training and so on. The underlying idea was the elimination of not only unemployment but also underemployment and the creation of decent work conditions.

(3) As for the specific promotional measures to the informal sector (producers/ enterprises), agriculture was separated from the non-agricultural sector. For the agricultural sector, the NCEUS argued for a focused strategy with respect to marginal and small farmers. A special programme was worked out to build capacity of small-marginal farmers through a group-based approach. These included (a) promotion of marginal-small farmers' groups, (b) greater access to institutional credit, training and capacity building, (c) support for strengthening and creation of non-farm activities, (d) gender-focused activities and (e) planning for development of marginal and small farmers given the ground reality of marginal and small farmers constituting 84 per cent of all farmers covering 50 per cent of the farm land.

(4) Access to credit was another major area. The existing two national institutions for refinancing - National Bank for Agricultural and Rural Development (NABARD) for agriculture and Small Industries Development Bank of India (SIDBI) for small-scale industries-hardly cater to the needs of micro-enterprises in the non-farm sector that dominate the non-farm informal sector. Such microenterprises were defined as those with investment of not more than Rs. 5 lakhs (as of 2009). Therefore, a National Fund for the Unorganised Sector (NAFUS) was recommended as a statutory body funded by the central government and financial institutions.

(5) Keeping in mind the special difficulties and barriers faced by the informal sector enterprises, a number of recommendations were also made for accessing technology, marketing and raw materials.

(6) Pulling together all the recommendations that are focused on the informal sector enterprises, the NCEUS suggested a cluster-based approach to the development 
of informal sector wherever feasible. By linking the clusters, a Growth Pole approach was also recommended emphasising the collective potential of the informal sector to the growth of the economy while creating decent work conditions for the workers. The creation of "Growth Poles involves an upscaling of cluster development efforts through provision of common infrastructure, service centres, etc., designed to take the existing cluster development approach to the next level. It is based upon strengthening natural clustering of industrial units to achieve economies of scale in skill acquisition, technology development, marketing, etc., assuming that clusters once developed would lead to a multiplier effect on production and employment as also a spread effect in rural areas" (NCEUS 2009: 374).

\section{Concluding Remarks}

The two major reports on (1) Conditions of Work and Promotion of livelihoods in the Unorganised Sector and (2) The Challenge of Employment: An Informal Economy Perspective (NCEUS 2008 and 2009) have discussed in detail the increasing dualism in India's economy as between the informal and formal economies and argued for a strategy of "levelling up" the informal economy. It is on this perspective that it developed a set of recommendations that have also been discussed in detail. In fact each set of major recommendations were followed with detailed reports. ${ }^{1}$

Two bills were drafted (one on 'Agricultural Workers' Conditions of Work and Social Security Bill, 2007" and another on "Unorganised Non-Agricultural Workers' Conditions of Work and Social Security, 2007") and submitted to the Government of India to ensure that the proposals on social security and conditions of work are to be legal rights and the schemes envisaged as entitlements to the workers qua workers.

But these were quietly ignored despite procedural scrutiny and a health-related social insurance system in the form of Rashtriya Swastha Bhima Yojana (RSBY) was enacted and implemented. It was a right-based one for the poor rather than as workers in the informal sector or informal employment. The work dimension was deliberately ignored by flagging the poverty alleviation/welfare dimension.

Some of the hard-core neoliberal leaders who contributed to the quite burial of the NCEUS recommendations are now advocating safety nets and cash transfers to the migrant and other informal labour. These calls sound so hollow given their past records of ignoring a number of NCEUS recommendations and watering down of some others but more importantly denying the work-related identity of the vast mass of labour in India.

\footnotetext{
1 These are: (1) Report on Definitional and Statistical Issues Relating to the Informal Economy (2008a), (2) Report on Social Security for Unorganised Workers (2006), (3) Reports on Financing of Enterprises in the Unorganised Sector and Creation of a National Fund for Unorganised Sector (2207), (4) A Special Programme for Marginal and Small Farmers (2008), (5) Report on Growth Pole for the Unorganised Sector (2009a), (6) Report on Skill Formation and Employment Assurance in the Unorganised Sector (2009b) and (7) Report on Technology Upgradation for Enterprises in the Unorganised Sector (2009c).
} 
Perhaps this is a time for a revisit and a re-examination of the recommendations of the NCEUS creating, for the first time, a larger architecture of social protection and social promotion for the informal workers and the informal sector in the country. It anchored all its recommendations in a larger macroeconomic objective of privileging decent employment as the overarching objective of economic development with growth as an enabler.

\section{References}

NCEUS (National Commission for Enterprises in the Unorganised Sector). 2008. Conditions of Work and Promotion of Livelihoods in the Unorganised Sector. New Delhi: Academic Foundation.

NCEUS. 2009. The Challenge of Employment: An Informal Economy Perspective. New Delhi: Academic Foundation.

Publisher's Note Springer Nature remains neutral with regard to jurisdictional claims in published maps and institutional affiliations. 